Journal of Sustainable Development of Transport and Logistics

journal home page: https://jsdtl.sciview.net

Hussain, N., Jovanović Popović, D., \& Milinčić, M. (2018). Modelling the environmental concerns of constructing the Danube-Morava-Vardar-Thessaloniki Canal using General Morphological Analysis. Journal of Sustainable Development of Transport and Logistics, 4(1), 6-16. doi:10.14254/jsdtl.2019.4-1.1.

\title{
Modelling the environmental concerns of constructing the Danube-Morava-Vardar-Thessaloniki Canal using General Morphological Analysis
}

\author{
Nasir Hussain *, Dejana Jovanović Popović **D, Miroljub Milinčić *** \\ * Strategy Foresight Ltd, \\ c/o: Bulman A Husain \& Co, 258 Merton Road, London SW18 5JL, United Kingdom \\ hussain@strategyforesight.org \\ ** Faculty of Security Studies, University of Belgrade, \\ 50 Gospodara Vučića St., 11000 Belgrade, Serbia \\ dejana@fb.bg.ac.rs \\ *** Faculty of Geography, University of Belgrade, \\ 3/III Studentski trg, 11000 Belgrade, Serbia \\ mikan@gef.bg.ac.rs
}

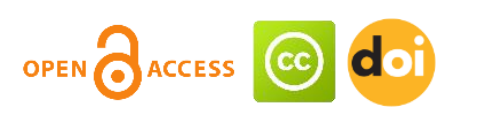

\section{Article history:}

Received: January 28, 2019

1st Revision: February 19,

2019

Accepted: March 29, 2019

\section{DOI:}

10.14254/jsdtl.2019.4-1.1

\begin{abstract}
The problem structuring method of General Morphological Analysis was used to explore the factors and uncertainties to be considered in the proposed building of a canal linking the Morava and Vardar Rivers, which in recent years has taken on greater importance given its possible link in China's one belt initiative. Facilitated workshop sessions identified five main factors - investors, risks, the motivation to invest, type of investment and long-term benefits - and 19 conditional states resulting in 1440 unique scenarios. Using specialist software and input from subject matter specialists from the fields of geography, environment and security, 81 scenarios were isolated. Modelling indicated that over twothirds of scenarios did not feature the impact on environmental damage such as raised pollution and effect on biodiversity. Interestingly, while financial institutions and the EU did feature because of reputational and ethical reasons, non-EU governments, construction firms and some regional governments did not. The implications of these findings warrant additional research but results of this study suggest that strengthening of governance would be required to mitigate impact on the local environment.
\end{abstract}

Keywords: modelling, canal, morphological analysis, MoravaVardar, China, problem structuring method. 


\section{Introduction}

The aim of this paper was to explore the use of General Morphological Analysis (GMA) as a Problem Structuring Method (PSM) to model the environmental impact in the construction of the canal linking the Morava and Vardar Rivers in Serbia and the Former Yugoslav Republic of Macedonia. Specifically, the study aimed to surface assumptions and uncertainties, identifying the possible unintended consequences such they can be mitigated before construction begins.

Our current investigation has been stimulated by the reported Chinese investment projects in Serbia, particularly in the area of transportation construction projects. Recent reports suggest that current and future projects could reach $\$ 10$ billion with much of it being realized within the China's "Belt and Road Initiative" ("The Chinese Wonder", 2019). This transcontinental project calls for the construction of faster railway lines, new ports, technological parks and motorways network with Serbia being in a pivotal and strategic link. For example, current shipments from China to the Piraeus port across the Indian Ocean and the Suez Canal shorten the transport time in about 10 days for Central or Eastern European countries, compared to alternative ports such as Rotterdam, Antwerp or Hamburg. Thessaloniki could offer additional capacity but would need the construction of the Morava-Vardar canal. Furthermore, in 2013 a Chinese state-controlled company submitted a planning report regarding the Morava valley with recommendations for construction of waterway and preliminary evaluation of needed investments, proposing to the Government of the Republic of Serbia to consider project, and define next steps. Whilst the report covered navigation, hydroelectric power generation, protection of water resources, water supply and irrigation, flood protection and tourism, we consider that additional research is required such that environmental impacts are mitigated for a sustainable future for the proposed canal.

The idea of connecting the Morava and Vardar rivers in the Balkan Peninsula by a canal (Fig. 1) to link northern European waterways to the Aegean Sea was first discussed as far back as the mid-19th century.

Figure 1: Proposed canal connecting the Morava and Vardar rivers

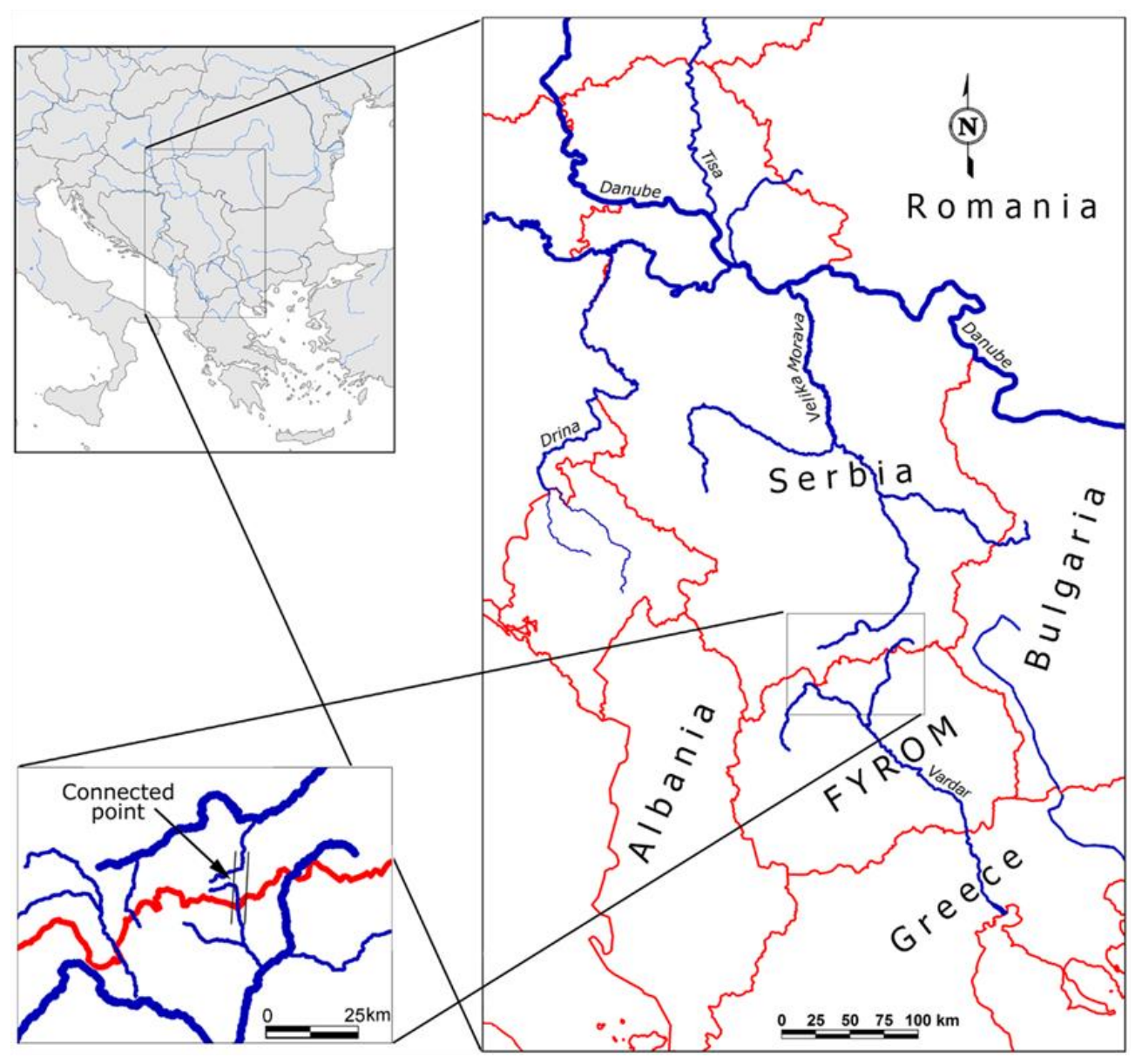


The chronological listing of attempts is given in Table 1 underlies the considerable strategic, geopolitical and socio-economic importance given to the region over the years. The construction of a canal from the Danube River to the port of Thessaloniki would significantly shorten the water-navigable route from Belgrade to Thessaloniki by approximately $1200 \mathrm{~km}$ compared to the existing route, which is via the Black Sea. Furthermore, Morava-Vardar canal would form a significant branch of the main European canal network, connecting Northern and Western Europe with the Mediterranean via the main European waterway (Rhine-Main-Danube).

Contemporary socio-political events both in the Balkan region and indeed within the wider European Union context and beyond, such as China's One Belt and One Road (Dimitrijevic, 2017) initiative, have re-initiated the feasibility of the project. For a land-locked country, not only does this provide Serbia (and its neighboring countries) an alternative shipping route but offers economic benefits since the basin of the river Morava covers a significant part of the territory, including Serbia's largest cities, main corridors, population and agricultural land. Furthermore, the regulation of the Morava River and its tributaries by constructing a flood protection and irrigation system, using its waters to supply neighboring cities and industries and possible generation of hydroelectric energy, could bring significant economic benefits to the central Balkan Peninsula.

\begin{tabular}{|c|c|}
\hline Time period & Description of activities \\
\hline 1869 & Steamship "Morava" built for research \\
\hline 1869 & Planned introduction of permanent navigation abandoned due to the lack of financial resources \\
\hline 1879 & $\begin{array}{l}\text { Serbian Learned Society publishes study "Morava, its current status and the possibility of } \\
\text { navigability" }\end{array}$ \\
\hline 1908 & $\begin{array}{l}\text { Society of American Engineers from New Jersey (USA) financially assist preparation of the } \\
\text { preliminary conceptual design of the waterway "Morava-Vardar" entitled "The line of European } \\
\text { economic gravity in relation to the Suez Canal" }\end{array}$ \\
\hline 1909 & $\begin{array}{l}\text { Report submitted to the governments of Serbia \& Turkey to begin preparatory work on the } \\
\text { project's further implementation. Political disagreements \& Balkan wars halts further efforts }\end{array}$ \\
\hline 1961 & Preliminary solution to the idea of the building canal Danube-Thessaloniki \\
\hline 1964 & $\begin{array}{l}\text { The study of navigation on the Great, South and West Morava river, with much more detail and } \\
\text { a more precise price estimation of investment costs }\end{array}$ \\
\hline 1966 & Program of the conceptual design of the waterway Morava-Vardar \\
\hline 1973 & nt to water management solut \\
\hline 1973 & $\begin{array}{l}\text { Based on the conceptual design and financial assessment of project, UN experts conclude that } \\
\text { canal could be economically justified. }\end{array}$ \\
\hline $1973-1980$ & Representatives of the UN revised and approved the project gaining international legitimacy \\
\hline 1990 & $\begin{array}{l}\text { EU funds study of management and development of elements of River Basin Management Plan } \\
\text { of Vardar River }\end{array}$ \\
\hline 2013 & $\begin{array}{l}\text { Memorandum on the canal project in the River Morava between Serbia and China. The concept } \\
\text { of spatial development of the waterway of the hydropower system Danube-Morava }\end{array}$ \\
\hline
\end{tabular}

Whilst the canal would 'only' necessitate the building of a $20 \mathrm{~km}$ stretch linking the Morava and Vardar rivers, there remain untold uncertainties that need to be carefully considered. Technical factors, such as geo-technical feasibility studies, potential demographic shifts etc., are usually of a semiquantitative nature that can be modelled with a certain degree of 'accuracy' compared to the subtler factors such as the effect on social capital, the effect of regional co-operation etc.

However, other uncertainties such as political developments in the EU, national and transnational security concerns such as the climate induced and/or political migration etc. are considerably more difficult, if not impossible to model. Such types of uncertainties, as opposed to a risk (which requires some form of probability distribution), fall into the category of unspecified uncertainty where the outcome space cannot be specified. In addition, there is the issue of so-called agnostic uncertainty (Ritchey, 2011), where there exists competing and cooperating actors, wills and intentions. In terms of a complex, self-referential system, this agnostic uncertainty refers to a network of conscious agents (individuals, organizations and nations) acting concurrently and reacting to each other. The behavior of this system is emergent and its development unpredictable. 


\section{Literature review}

There exists a paucity of articles in the published literature that document decision-modelling of multiple and interrelated socio-technical, geo-political and environmental factors in the construction of large-scale infrastructure projects, and even less so when it comes to the use of problem structuring methods (PSM). For example, He et al (2009) only reported the use of environmental audits for the Qinghai-Tibet Railway in China without taking into account of other factors such as the development of sociological and urbanization developments that are naturally associated with large-scale building projects. Such projects are bedeviled with the facilitation of a wide group of stakeholders that policymakers need to take into account such as demographers, security personnel, environmentalists, politicians, public and industrialists. Typically, such 'wicked problems', as described by Rittel and Webber (1972), are characterized by complexity, a high degree of uncertainty and multiple subjectivity. Structuring them into a form in which they can be addressed is at least as challenging as formally solving them using PSM and cognate approaches. Ng et al (2007) have developed dispute avoidance and resolution techniques (DART) for resolving conflicts amongst project managers in the delivery of infrastructure projects but did not take into account in their paper of other stakeholders other than those in the construction sector. A better approach is that taken by Foote et al (2006) who used a multimethodological approach known as systemic intervention to address management of ongoing water shortages in a small seaside town in New Zealand. Such boundary critique, a theory and set of methodological ideas for exploring the inclusion, exclusion and marginalization of both people and issues, led to the design of a participative problem structuring workshop, identifying a way that both the District Council and community could accept, yet this project involved a smaller, non-constructionbased project. Whilst PSM address 'what to do with the problem now', Hong et al (2011) simulated the impacts of policy scenarios on the sustainability performance of infrastructure projects using system dynamics, a form of PSM, to evaluate the sustainability performance of highway infrastructure projects during the construction and operation stage. Whilst their results introduced indicators which measured the sustainability performance of highway projects and identified the dynamic factors affecting indicator performance by referring to the relevant feasibility studies of highway projects, they relied upon their own observations and studies rather than include a diverse set of stakeholder views. Nevertheless, their case study explored solutions for improving poor sustainability performance areas through policy scenarios. As can be seen, there appears to be no directly comparable research in large scale infrastructure projects that we have sought to explore and report in this paper. Additionally, our research falls into the Brundtland Commission Report of 1987 that aims to unite countries to pursue sustainable development together that addresses, amongst other items, economic growth, environmental protection and social equality (World Commission on Environment and Development, 1987).

\section{Research methods}

Regardless which type of uncertainty one is dealing with, these are inherently ineradicable i.e. one cannot obviate it simply by trying to obtain more information because the information required to reduce the uncertainty it is not available. Such problems are typically characterized by complexity, a high degree of uncertainty and multiple subjectivity, characteristics of what has been termed a 'wicked problem' (Hussain \& Ritchey, 2011). Structuring them into a form in which they can be addressed is at least as challenging as formally solving them. As an alternative to mathematical modelling, several nonquantified PSM have been developed over the past 40 years in the European Operational Research field. These methods are designed for use in the context of workshops in which the problem owners are central participants and emphasize qualitative rather than quantitative content to mitigate uncertainty, develop contingency plans and options for project development. Here we have used GMA as a PSM and as a decision support modelling tool to address the various uncertainties and their associated intended, and unintended, consequences in building the canal.

GMA is a method for structuring and investigating the total set of relationships contained in multidimensional, problem complexes formalized by Zwicky (1948) during his work in engineering and astrophysics. The technique has been extended and applied by a number of researchers in the field of futures studies, policy analysis and strategy modeling. The most notable recent extension has been by 
Ritchey (2011) who added the internal Cross Consistency Assessment (CCA) during their development in the 1990s of a computer support system for GMA at the Swedish Defense Research Agency. This made it possible to create inference models, significantly extending GMA's functionality and areas of application in a variety of areas such as structuring complex policy and planning issues, developing scenario and strategy laboratories, and analyzing organizational and stakeholder structures.

Four workshop face to-face session (each lasting a day) and $6 \times 2 \mathrm{~h}$ teleconferences were required for the project involving experts from the disciplines of security, environmental, geology, demography and economic studies. GMA modelling was conducted in two parts: i) problem space field construction: identifying and defining the most important parameters (dimensions) of issues in the building of the canal, and assigning each parameter a range of relevant mutually-exclusive conditions, and ii) solution space construction: performing the cross-consistency assessment, a form of a cross impact matrix, which involves comparing each and every parametric condition with another from a different parameter in a pairwise manner. As each pair of conditions is examined, a judgment is made as to whether - or to what extent -the pair can coexist, i.e. represent a consistent relationship. Note that there is no reference here to causality, but only to internal consistency or mutual compatibility. The workshop was led by a GMA facilitator and required the use of software to 'weed out' the mutually contradictory pairs. It should be noted that the requirement for software is not an absolute requirement for this analysis as the CCA can be done manually using a mathematical formula (Luckman, 1967).

Pairwise assessments were conducted and scored as i) conditional, supportive, or independent (''), ii) obstructive ('P'), or iii) contradictory (X). The P score is, in effect, an empirical constraint in that the pairwise relationship is not completely contradictory but is conditional or supportive dependent upon additional factors such as time, cost, future technical development etc. This reflects the uncertainty between the two options being considered. For both the problem space (analysis) and solution space (synthesis) modes, these key uncertainties were captured as denoted by a red dot in the top right-hand side of a cell behind which the dialogue box recorded a description.

\section{Research results}

Five parameters (aka dimensions) were identified with three to six options per parameter resulting in 1440 unique possible scenarios (Fig. 2).

Figure 2: Initial morphological field containing six dimensions 1440 possible scenarios

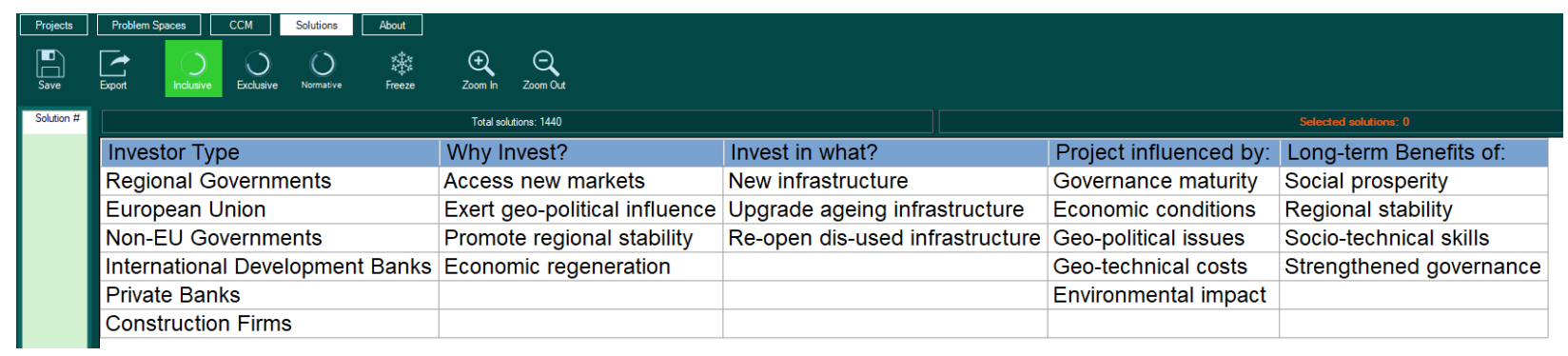

The CCA contained 142 pairs (Fig. 3) and demonstrates the power of the reductive method whilst each addition of dimension results in an exponential increase in the configurations (scenario space), the CCA matrix only grows only as a quadratic polynomial - more specifically, in proportion to the triangular number series as exemplified in Figure 4. This makes it possible only to perform a small number of comparisons to reduce the possible configurations to a manageable number for policymakers, modelers and scientists to consider. The two types of inconsistencies in the CCA are denoted by $\mathrm{X}$ and $\mathrm{P}$, where $\mathrm{X}$ denotes a purely logical contradiction (i.e. based on the nature of the concepts involved) while $\mathrm{P}$ is an empirical constraint (i.e. relationships judged possible but unlikely). Normative constraints can also be applied, although these must be used with great care and were not used in the modelling. 
Figure 3: Compatibility grid containing $\mathrm{X}$ pairs of assessments

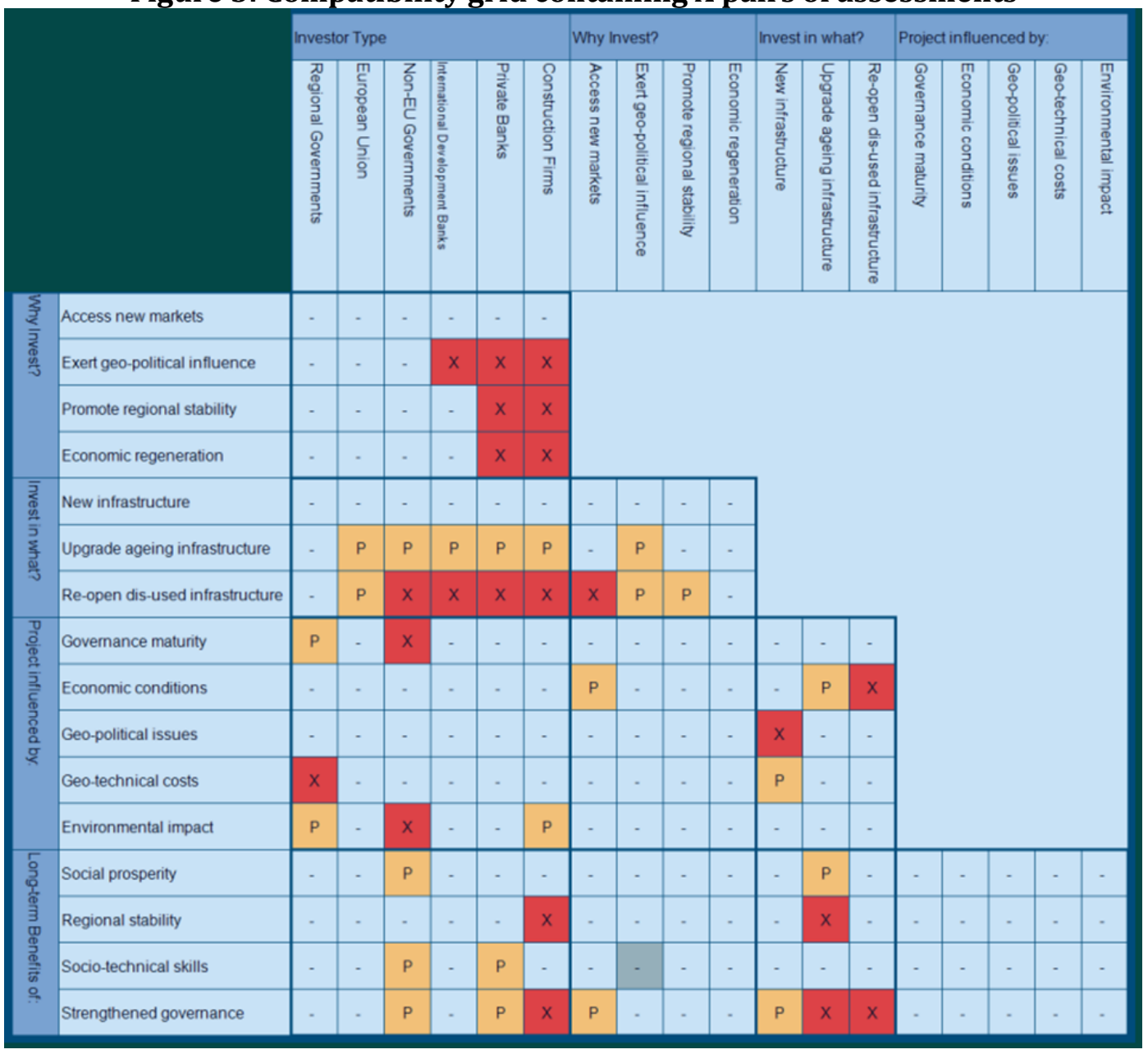

Note: The red dot denotes a comment box to retain notes of how and why the assessment was made to maintain an audit trail

Figure 4: Divergence between the increase in the total number of configurations in the problem space versus the total number of pairwise cells that need to be assessed in the CrossConsistency Assessment (CCA)

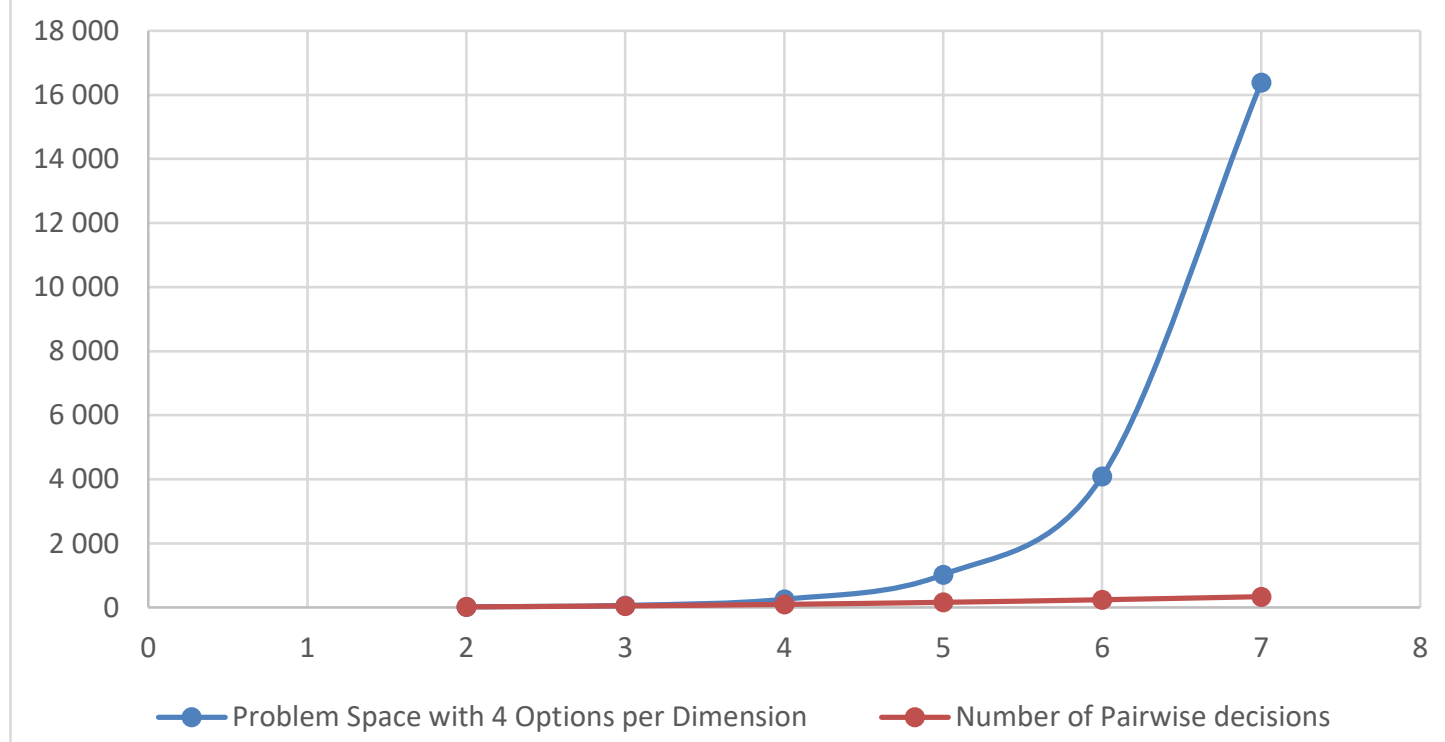

Note: Practice has shown that even if only $20 \%$ of CCA are assed for X, P or -, greater than $90 \%$ of total configurations in the problem space can be eliminated 


\begin{tabular}{lcc}
\hline Dimensions & Problem Space with 4 Options per Dimension & Number of Pairwise decisions \\
\hline 2 & 16 & 16 \\
3 & 64 & 48 \\
4 & 256 & 96 \\
5 & 1,024 & 160 \\
6 & 4,096 & 240 \\
7 & 16,384 & 336 \\
\hline
\end{tabular}

Forty-five pairwise assessments by the workshop team resulted in 81 strict options (aka configurations or scenarios), a reduction of over $94 \%$ in the problems space (Fig. 4). The resulting inference model forms the basis of a 'conceptual laboratory' where any cell shown in red can be selected to show the possible mutually compatible conditions, which are shown in blue.

\section{Figure 5: The solution space shows 81 options (out of a possible 1440) in the (strict) exclusive mode, where $P$ is treated as an $X$}

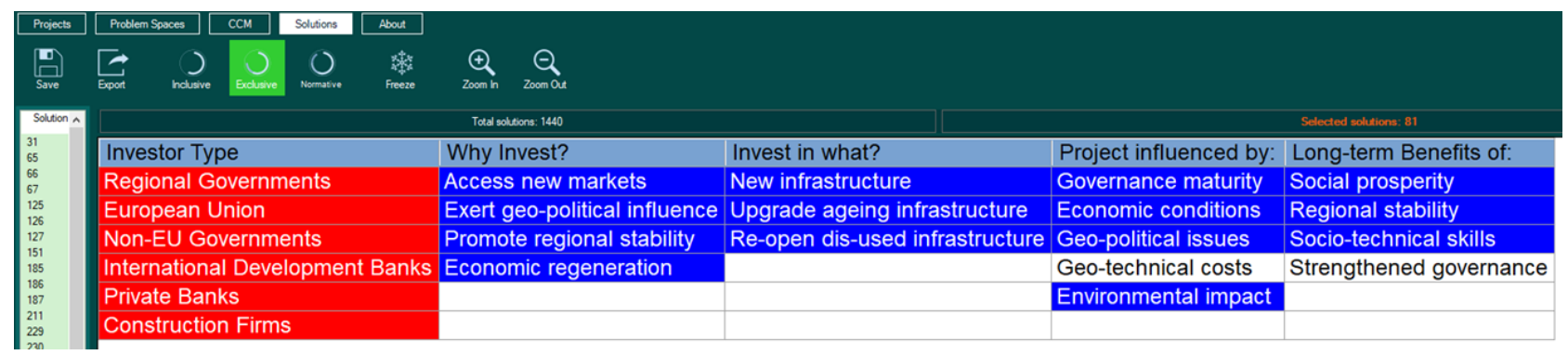

Note: Note that the in the tool bar 'Exclusive' is shaded in green and the number of solutions shown in red text in top right-hand side

Since the main concern here was on the environmental impact, Figure 5 shows that of 12 options, non-EU governments and their associated construction firms were unlikely to consider environmental risk posed by the canal's construction as major risk, their prime motivation likely being driven by the desire to regenerate the local and regional economies to rapidly bring social prosperity, regional stability and gain in new socio-technical skills. It was worth noting here that the 12 options resulted when the model was relaxed to the inclusive mode, where $P$ behaves as a '-'; exclusive mode resulted in zero configurations. It is for this reason that GMA is sometimes refereed to Field Anomaly Relaxation in the literature whose main proponents used the technique for scenario development (Rhyne, 1981).

Figure 6: Strengthening governance requirements to mitigate environmental impact appears to be mainly in the development of new infrastructure driven by regional governments via the European Union and financial institutions

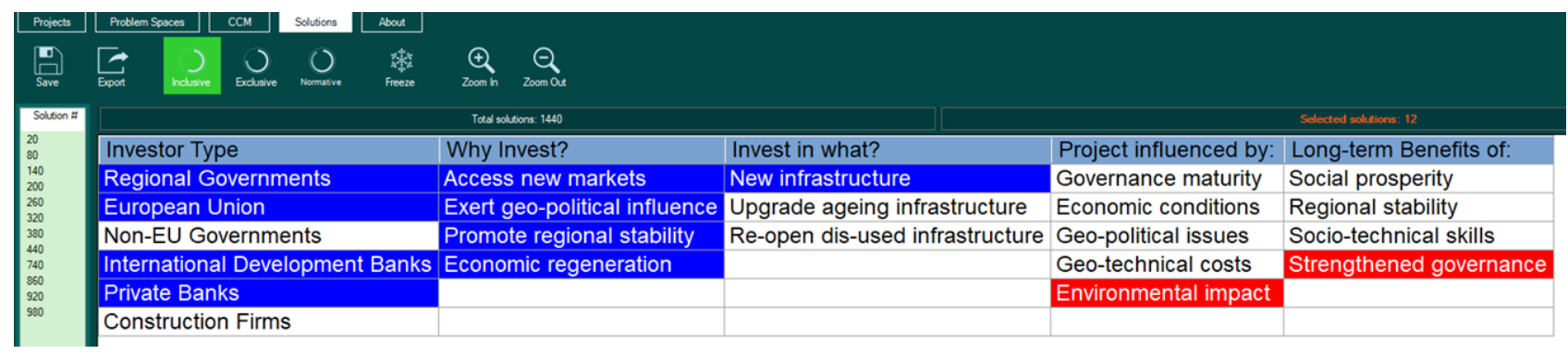




\section{Discussion of the results}

Although a wide variety of problematic situations have been tackled using PSMs (Mingers \& Rosenhead, 2004), those involving large scale construction projects, particularly water-based ones are relatively scarce. Franco, Cushman \& Rosenhead (2004) used the PSM of the Strategic Choice Approach, whose first two stages are similar to GMA, in the construction industry where multi-organizational partnerships are a common feature. Their findings showed that a major construction company using PSMs had a more effective mechanism for learning from past projects, and for increasing the involvement of supplier partners, something that would be needed for the Morava-Vardar canal project. The academic literature reporting the multi-disciplinary aspects of projects involving canal development are uncommon but a small number do exist such as recent research into impact of the Carat Canal on the evolution of hub ports under China's Belt and Road initiative (Zeng et al., 2018) and analysis of future land use changes and water availability in the Nicaraguan Southwest as a result of the construction of the interoceanic canal (Ardila et al., 2017). It would be prudent for policymakers and technical decision makers to consult such material.

In terms of the environmental impact in the case of the Morava-Vardar canal, Table 2 illustrates the major risks identified during the course of the GMA modelling process: flood protection, water supply, increase in water traffic and the effects on local and regional ecology.

Table 2. Uncertainties uncovered during the modelling workshop

Uncertainties about

working details on:

\begin{tabular}{ll}
\hline Flood Protection & Requirement to regulate the Morava \\
& river and its tributaries by \\
& constructing the flood protection \\
system
\end{tabular}

Water supply

Water traffic

Effects on local ecology
Despite 23 reservoirs in the Morava Valley, water quality is already low and distribution system eroded

None exists presently as the canal needs to be built

Industrial waste water and sewage from households from settlements on both sides are discharged directly into the river with a few protective treatments
Research required on associated risks
Type of flood defenses at known flooding points such as embankments and flood control reservoir required, material used in the construction and effect on local ecology

increase in the assurance rate of ecological water would improve water supply to human and for irrigation at the cost of displacement of local fauna and species

Increase in water-based transit for commercial use and tourism and impact on quality of water, and thus on the local environment, as result of pollution in an area currently unaffected by human-made waste

Canal building and use would increase discharges and distribute to a wider area compared to the present situation which could affect distant regions currently unaffected. Introduction of foreign invasive species could displace native species and have unintended consequences on both local and regional ecology

Figure 7 shows 23 scenarios in this case but note the strengthened governance did not feature in any. It is a feature of PSM like GMA that such uncertainties are surfaced as a result of the unique interplay not only because of the analysis and synthesis modes of the modelling method but because of the discourse that results as one clearly defines the parameters and options in the morphological field, and particularly during the CCA. As far as the authors are aware, none of uncertainties raised, and the proposed research to investigate and mitigate these, have been identified explicitly by policymakers and 
proponents of the canal. Note that all four of the uncertainties could impact on each other e.g. the increase in water-based transit for commercial use and tourism likely impacts on the water quality, and thus on the local environment, as result of pollution in an area currently unaffected by man-made waste, which could spread further afield. Local intelligence indicates that financing the canal construction is a major issue with concessionary loans as the main financing route, which could hamper environmental protection considerations.

\section{Figure 7. An example of the resulting 'solution space' following the CCA. By selecting 'Environmental impact' as a driver, 23 solutions are obtained listed on the right-hand side that can be drilled down further by selecting another parametric condition}

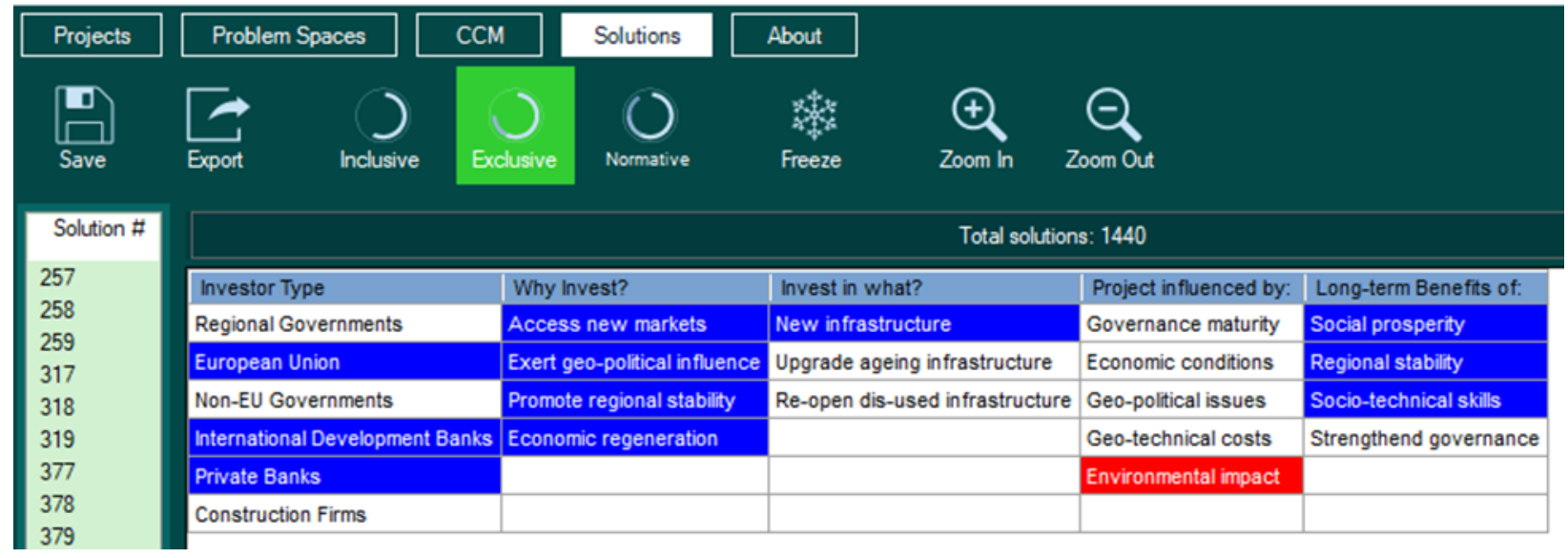

Added to this, the modelling surfaced the issues around governance and transparency and the passing of legislation in the affected countries of Serbia, FYROM and Greece, the latter also being member of the European Union. As a result, new socio-technical skills need to be identified and developed that could be hastened by joint administration of the canal and cognate issues of integrated water management in the canal zone as in the case of severe flooding or even droughts at the other end of the spectrum

Specifically, for a water-based project, Gregory et al (2013) employed the Drivers - Pressures State Changes - Impacts - Responses (DPSIR) approach, which has been recently classified as a PSM, in the context of studying complex adaptive systems for water management. Their findings indicated to not only to recognize a broad range of stakeholders (a question of boundary critique) but to manage competing knowledge parameters (economic, local and scientific) and value claims. Our exploratory study here shows how GMA can parametrize a complex problem where the morphological field represents a bounded critique encompassing a total set of possible conditions. While mathematical modelling should be used where possible, such as Ungureanu's study (2009) on dynamical modelling of water pollution using past macro-economic data, at a certain level of complexity and uncertainty judgments must often be used - and worked with - more or less directly. PSMs such as GMA allow such judgmental processes to be placed on a sound methodological basis, with a digital audit trail, to give decision makers the systematic support in identifying a consensual framework for engaging with their complex problems.

\section{Conclusions}

Of the 81 consistent scenarios from a possible set of 1440, only 23 considered the environmental impact of the canal's construction, further reduced to 12 if the option of strengthened governance was selected as a consideration. Regional and non-EU governments nor non-EU construction firms featured in these scenarios suggesting Environmental, Sustainability and Governance (ESG) standards need to be strengthened to give confidence to stakeholders. The use of GMA as a PSM has shown good feasibility as a modelling approach to further support its use for large-scale construction projects, and while the paper has concentrated on environmental aspects, future research would need to take account of other interrelated factors such as changes in demographics and development of new sociotechnical skills and social capital. 


\section{Citation information}

Hussain, N., Jovanović Popović, D., \& Milinčić, M. (2018). Modelling the environmental concerns of constructing the Danube-Morava-Vardar-Thessaloniki Canal using General Morphological Analysis. Journal of Sustainable Development of Transport and Logistics, 4(1), 6-16. doi:10.14254/jsdtl.2019.4-1.1.

\section{References}

Ardila, A. M., Rebscher, A. \& Hack, J. (2017). Analysis of future land use changes and water availability in the Nicaraguan Southwest as a result of the construction of the Nicaragua Interoceanic Canal. Preprints, 2017090045. Retrieved January 19, 2019 from https://www.preprints.org/manuscript/201709.0045/v1

Dimitrijević, D. (2017). Chinese Investments in Serbia - A Joint Pledge for the Future of the New Silk Road. Baltic Journal of European Studies, 7, 64-83. https://doi.org/10.1515/bjes-2017-0005

Foote, J. L., Gregor, J. E., Hepi, M. C., Baker, V. E., Houston, D. J., \& Midgley, G. (2007). Systemic problem structuring applied to community involvement in water conservation. Journal of the Operational Research Society, 58, 645-654. https://doi.org/10.1057/palgrave.jors.2602248

Franco, L. A., Cushman, M., \& Rosenhead, J. (2004). Project Review and Learning in the Construction Industry: Embedding a Problem Structuring Method within a Partnership Context. European Journal of Operational Research, 152, 586-601. https://doi.org/10.1016/S0377-2217(03)00059-6

Gregory, A. J., Atkins, J. P., Burdon, D. \& Elliot, M. (2013). A Problem Structuring Method for EcosystemBased Management: The DPSIR Modelling Process. European Journal of Operational Research, 227, 558-569. https://doi.org/10.1016/j.ejor.2012.11.020

He, G., Zhang, L. \& Lu, Y. (2009). Environmental Impact Assessment and Environmental Audit in LargeScale Public Infrastructure Construction: The Case of the Qinghai-Tibet Railway. Environmental Management, 44, 579-589. https://doi.org/10.1007/s00267-009-9341-5

Hussain, N., \& Ritchey, T. (2011). Wicked Problems. European Journal of Industrial Pharmacy, 31, 4-7. http://www.swemorph.com/pdf/wp-pharma.pdf

Luckman, J. (1967). An Approach to the Management of Design. Journal of Operational Research Society, 18, 345-358. https://doi.org/10.1057/jors.1967.68

Mingers, J. \& Rosenhead, J. (2004). Problem Structuring Methods in Action. European Journal of Operational Research, 152, 530-554. https://doi.org/10.1016/S0377-2217(03)00056-0

Ng, H. S., Peña-Mora, F., \& Tadatsugu, T. (2007). Dynamic Conflict Management in Large-Scale Design and Construction Projects. Journal of Management in Engineering, 23, 52-66. https://doi.org/10.1061/(ASCE)0742-597X(2007)23:2(52)

Politica. (2019, January 5). The Chinese wonder in Serbia, investments of nearly $\$ 10$ billion. Retrieved January 19, 2019 from http://www.politika.rs/scc/clanak/419657/Kinesko-cudo-u-Srbijiinvesticije-od-blizu-10-milijardi-dolara

Rhyne, R. (1981): Whole-Pattern Futures Projection Using Field Anomaly Relaxation. Technological Forecasting and Social Change, 19, 331-360. https://doi.org/10.1016/0040-1625(81)90005-6

Ritchey, T. (2011) Wicked Problems-Social Messes: Decision Support Modelling with Morphological Analysis. Berlin: Springer Verlag. https://link.springer.com/book/10.1007\%2F978-3-642-196539

Rittel, H.W.J. \& Webber, M.M. (1973). Dilemmas in a General theory of Planning. Policy Sciences, 4, 155169. https://doi.org/10.1007/BF01405730

Ungureanu, L. (2009). A Dynamical Model of Water Pollution. Journal of Environmental Protection and Ecology, 10, 23-31. Retrieved from https://docs.google.com/a/jepe- 
journal.info/viewer?a=v\&pid=sites\&srcid=amVwZS1qb3VybmFsLmluZm98amVwZS1qb3VybmFs fGd4Ojc0YzU4MzQzZjY0MzZkM2Y

United Nations (1987). Report of the World Commission on Environment and Development https://en.wikisource.org/wiki/Brundtland_Report

Zeng, Q., Wang, G. W. Y., Qu, C. \& Li, K. X. (2018). Impact of the Carat Canal on the evolution of hub ports under China's Belt and Road Initiative Transportation Research Part E: Logistics and Transportation Review, 117, 96-107. https://doi.org/10.1016/j.tre.2017.05.009

Zwicky, F. (1948). The Morphological Method of Analysis and Construction. New York: Interscience.

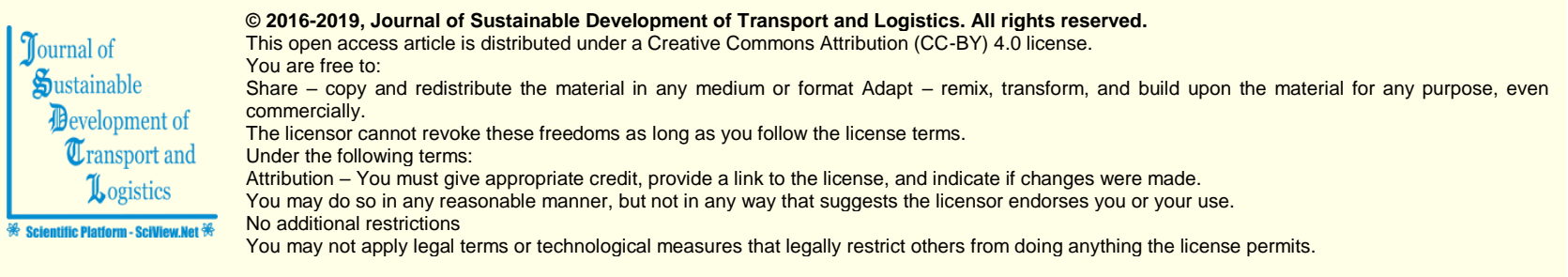

Journal of Sustainable Development of Transport and Logistics (ISSN: 2520-2979) is published by Scientific Publishing House "CSR", Poland, EU and Scientific Publishing House "SciView", Poland, EU

Publishing with JSDTL ensures:

- Immediate, universal access to your article on publication

- High visibility and discoverability via the JSDTL website

- Rapid publication

- Guaranteed legacy preservation of your article

- Discounts and waivers for authors in developing regions

Submit your manuscript to a JSDTL at https://jsdtl.sciview.net/ or submit.jsdt|@sciview.net 